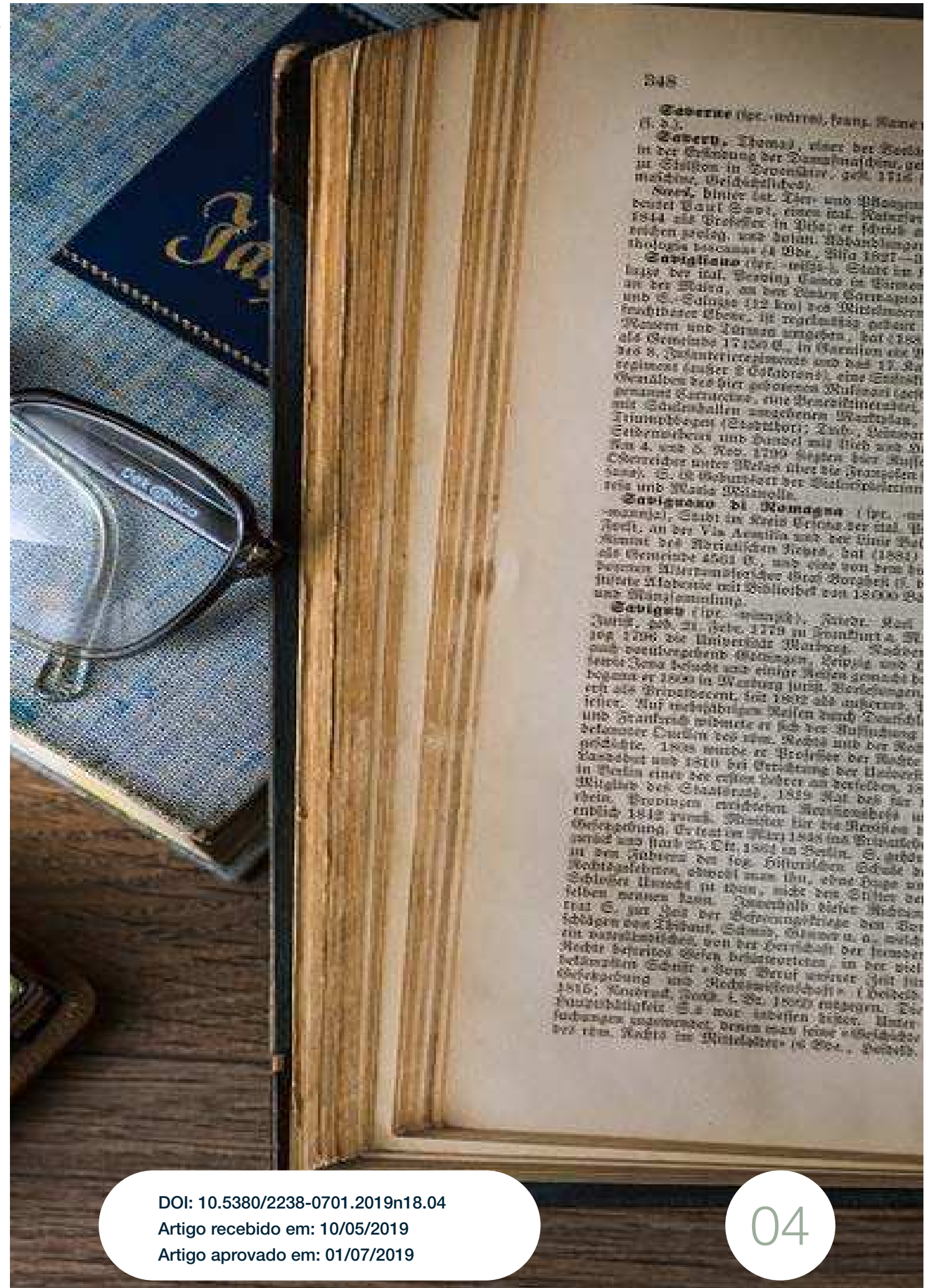


Mídia e história na Teoria Alemã das Mídias 


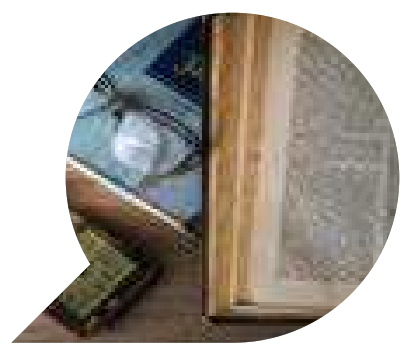

\title{
Mídia e história na Teoria Alemã das Mídias
}

\author{
Media y historia en la teoría alemana de los médios
}

Media and history in German media theory

\section{MARCIO TELLES ${ }^{1}$}

Resumo: $O$ artigo investiga como as palavras mídia e história são empregadas dentro dos textos teóricos da Teoria Alemã das Mídias. Afirma-se que problemas, soluções, metodologias e pressupostos teóricos encontrados dispersos em vários autores identificados com a TAM não são fortuitos, mas expressões produtivas do agenciamento constituído ao redor dessas palavras, que funcionariam como atratores teóricos dentro de uma rede discursiva. Estuda-se como mídia é usada (mas não conceituada), em Kittler, e em como "pós-história", constituída na negação de história, substancia a Arqueologia das Mídias.

Palavra-chave: Epistemologia da comunicação; Palavras-chave; Teoria Alemã das Mídias.

Resumen: El artículo investiga cómo las palabras media e historia se emplean dentro de los textos teóricos de la Teoría Alemana

1 Professor da Universidade Federal do Espírito Santo, Vitória, Espírito Santo, Brasil. Doutor em Comunicação e Informação pela Universidade Federal do Rio Grande do Sul, com estágio doutoral na Winchester School of Art, Universidade de Southampton, Inglaterra, Reino Unido. A pesquisa que originou este artigo foi financiada pela CAPES. 
de los Medios. Se afirma que problemas, soluciones, metodologías y presupuestos teóricos encontrados dispersos en varios autores identificados con la TAM no son fortuitos, sino expresiones productivas del agenciamiento constituido alrededor de esas palabras, que funcionarían como atractores teóricos dentro de una red discursiva. Se estudia cómo Kittler se utiliza de la palabra media y en como "post-historia", constituida en la negación de historia, sustancia la Arqueología de los Medios.

Palabras clave: Epistemología de la comunicación; Redes discursivas; Teoría Alemana de los Medios.

\begin{abstract}
The paper shows how the words media and history work within German Media Theory's texts. As a hypothesis, the paper states that problems, solutions, methodologies and theoretical assumptions scattered through various authors within the GMT tradition are not random; instead, they are productive expressions of the discourse network built around these words. The paper shows how Kittler uses the word media and how "post-history" sanctions Archaeology of Media's point of view on history.
\end{abstract}

Keywords: Discourse networks; German Media Theory; Keywords

\title{
1. Introdução
}

No nível mais geral, a Teoria Alemão das Mídias (TAM) propõe um tipo de investigação a respeito das condições de possibilidade de uma (materialidade de) mídia específica. Para a TAM, as mídias que emergem dentro de situações particulares têm consequências, muitas vezes imperceptíveis, em como o mundo é percebido e habitado, e sobre aquilo que é possível comunicar em cada época e por meio de cada mídia. Consequentemente, entende que essas mesmas situações são fruto e consequência de experiências contingentes a um período de tempo. Também percebe que os próprios processos de subjetivação são a consequência do engajamento dos humanos com as mídias, da mesma maneira que visões de mundo são inseparáveis de suas medialidades. 
Tudo a partir do pressuposto metodológico de que a materialidade da mídia (FELINTO, 2001) é o ponto inicial de investigação.

O programa de pesquisa esboçado acima é, reconhecidamente, um construto artificial agenciado mais por comentadores internacionais de alguns autores alemães do que propriamente por um conjunto homogêneo de projetos. Para os alemães, esse construto estrangeiro desfigura propostas teóricas distintas e programas de pesquisa particulares (GEOGHEGAN, 2013; SPRENGER, 2016): a German Media Theoryé ao mesmo tempo menor e maior que as Medienwissenschaften (SPRENGER, 2016, p. 85) alemãs e suas abordagens correlacionadas, como Medienarchäologie e as Kulturtechniken². Isso não exclui, todavia, a existência de um mínimo denominador comum que, no nosso entender, dar-se a ver na maneira como algumas palavras-chave são empregadas pelos autores, o que demonstraria - mais do que as propostas teóricas e os programas particulares de pesquisa - a existência de um caldo intelectual comum. Logo, se uma primeira questão é delimitar quais textos podem ser incluídos no rol da TAM - pois, evidentemente, não é possível, nem desejável, afirmar que tudo aquilo que é produzido teoricamente na Alemanha possa ser chamado de TAM -, o que parece estar a priorido núcleo duro de pressuposições teóricas são os usos compartilhados dessas palavras-chave.

Logo, o desafio é entender o pensamento teórico alemão das mídias em relação a si próprio e ao ambiente (ou à situação) em que é gestado. A hipótese de fundo é que certas palavras-chave (WILLIAMS, 2015) e suas "formações de sentido" servem como atratores, elementos dispersos em um espaço topológico na direção dos quais uma rede discursiva (KITTLER, 1990) tende a evoluir. A profundidade semântica delas é perfeitamente clara para os estudiosos alemães, mas não é possível dizer que se reportem de igual maneira ao entendimento comum do leitor brasileiro. A falta de compreensão a respeito dessas nuanças trunca a recepção dos textos: o que os autores da TAM compreendem quando falam em mídia e história, por exemplo, é diferente do que nós, brasileiros, compreendemos quando ouvimos (e falamos) de mídia e história. Logo, reconhece-se a existência de problemas comunicacionais

2 Em tradução livre, respectivamente: Estudos de Mídia, Arqueologia das Mídias e Técnicas Culturais. Esses três conjuntos podem ser identificados, de maneira bem provisória, com os desenvolvimentos teóricos respectivos aos anos 1980, 1990 e à segunda década do século XXI, pós-falecimento de Friedrich Kittler, em 2011. 
nos processos tanto de produção quanto de recepção de teorias a respeito de mídias.

Tal foco nos conceitos e em sua dimensão semântica, assim como o posicionamento destes como subsidiários epistêmicos, possui um grande lastro na história do pensamento e dos sistemas filosóficos ${ }^{3}$. Um dos trabalhos mais significativos do uso performático das palavras dentro de contextos socioculturais específicos é Keywords, do britânico Raymond Williams (2015). Williams compreendia a língua como causativa, capaz de exercer uma força social estruturante, ainda que não independente dos comunicadores humanos e seus usos desejados e desejáveis, substanciando o insight do polemista francês Alexis de Tocqueville (2010, p. 326) de pensar a língua como "o primeiro instrumento do pensamento". Para Williams (2015, p. xxiv, tradução nossa) palavraschave são "palavras significativas e obrigatórias em certas atividades e [em] sua interpretação; [e] palavras significativas e indicativas em certas formas de pensamento".

Para os interesses deste artigo, a rede a ser estudada é aquela desenhada do conjunto de hipóteses e suposições que orbitam em direção a, e a partir de, duas palavras-chave: mídia e história. No nosso entender, compreender o sentido específico com que o termo mídia (mas não o conceito) é empregado pelos teóricos alemães abre as possibilidades de um estudo comparado de proposições teóricas. Para os teóricos alemães, os modos como empregam palavras como mídia e história são absolutamente claras. A maneira como esses termos são tomados por naturais, assim como as valorações que ocultam e o que é tido como implícito quando cada uma das palavras é invocada, torna difícil transpô-las a um estrangeiro. Ao fim e ao cabo, é essa externalidade dos termos que apontam para o entendimento epistemológico produtivo de uma rede discursiva teórica.

A seguir, em duas breves seções, apontaremos os desenvolvimentos teóricos associados à teoria de Kittler e aos pressupostos da Arqueologia das Mídias como dependentes de dois entendimentos de termos específicos (as palavras-chave) que são incontornáveis à reflexão desses autores, mas que se encontram a priori de seus pensamentos. Elas - as

3 Cito, muito brevemente, os nomes de Gilles Deleuze, Jacques Derrida, Michel Foucault e Raymond Williams como autores que já se debruçaram em investigações semelhantes. 
palavras mídia e história - são a matéria que empregam para "in-formar" suas reflexões, mas não são de maneira alguma neutras de significado. $O$ que elas trazem consigo são determinantes para a maneira específica de pensar a respeito dos meios, o que justificaria - como tentarei desenvolver na conclusão - o enquadramento dos autores em uma "Teoria Alemã das Mídias”, por mais que os alemães desgostem do termo.

\section{2. "Mídia" em Kittler}

Naquele que talvez seja o exemplo mais famoso da teoria das mídias de Friedrich Kittler (1990, p. 191-198; cf. também em KITTLER, 1999, p. 202-206), o filósofo Friedrich Nietzsche, em uma carta a um amigo compositor, sugere que "Nossas ferramentas de escrita também operam sobre os nossos pensamentos". Debilitado pela miopia e por fortes dores de cabeça que prejudicavam o tempo que dedicava à escrita e à leitura, Nietzsche adquirira nos últimos anos de sua vida uma máquina de escrever primitiva - uma "writing ball" dinamarquesa Malling Hansen que não o permitia ver a letra escolhida no ato de datilografar. Seu amigo notou mudanças em seu estilo de escrita: a prosa de Nietzsche tornarase diminuta, direta, quase telegráfica. Segundo Kittler,

Nietzsche [...] mudou de argumentos para aforismos, de pensamentos para trocadilhos, de retórica para o estilo de telegrama. É precisamente isso que significa a frase que nossas ferramentas de escrita também estão trabalhando em nossos pensamentos. A bola de escrever de Malling Hansen, com suas dificuldades operacionais, transformou Nietzsche em um lacônico (KITTLER, 1999, p. 203, tradução nossa).

O que Kittler tenta operar é a redução do arquivo foucaultiano às características materiais enquanto sinônimo para "mídia". A partir daí, os limites do comunicável equivaleriam aos limites da medialidade. É o que Kittler (1999, p. xxxix, tradução nossa) quer dizer com a emblemática frase que abre Gramophone, Film, Typewriter: "A mídia determina nossa situação". As mídias "atuam" sobre nossos pensamentos precisamente porque são elas que ofertam o universo do comunicável (dos visíveis e dos enunciáveis): não existe comunicação sem elas. Na verdade, 
qualquer forma de sensação é, a priori, impossível: o corpo humano é anestesiado sem elas. Kittler inverte a proposição mcluhaniana: as mídias não são mais a extensão do homem; é o humano a extensão das mídias.

Isto descansa sobre uma compreensão particular da palavra "mídia", substanciada por uma forte tradição germânica, que Kittler "contrabandeia" para dentro de sua obra. Nesse sentido, Kittler também seria o resultado de sua rede discursiva. Nela, Aristóteles é nomeado o "primeiro teórico da mídia" (SEITTER, 2015), quiçá o primeiro teórico alemão de mídias. Para Aristóteles "há sempre um atributo sensível que causa um movimento no medium (ar, água ou terra), que por sua vez produz movimento nos órgãos do sentido. Com isso, os corpos só são percebidos na medida em que atributos sensíveis movimentam o medium" (BASTOS, 2012, p. 56). Se Kant afirmava que a imagem do mundo "lá fora" é definida pelas características de nosso aparato intelectual, que define a priori nossas experiências a posteriori, Kittler preocupa-se que nosso aparelho psíquico é, senão moldado, ao menos entremeado pelas mídias que utilizamos, ou seja, todo a priori intelectual é, na verdade, um a priori medial. Não existiria significação fora das mídias (e sua base material), pois não existiria sequer a possibilidade de percepção. Isso significa que é a mídia que produz a presença de algo que até então estava além ou aquém do nosso limiar perceptivo. Uma nova mídia, portanto, muda as fronteiras do visível e do enunciável - daquilo que pode ser percebido - em uma determinada época, logo, também do comunicável.

Todavia, há uma distinção na maneira como medium e mídia estão relacionados, ainda que nem sempre esse entendimento seja evidente ou mesmo consciente por parte dos autores. O conceito de mídia é dividido em duas grandes categorias: as suas formas materiais superfícies -, e o medium ou meio propriamente dito, atingido sempre de forma enviesada a partir da descrição cuidadosa da materialidade manifestada. A partir daí, a mídia é pensada como o agenciamento ad hoc de elementos heterogêneos - de "aparatos técnicos, códigos, sistemas simbólicos, formas de conhecimento, práticas específicas e experiências estéticas" (VOGL, 2007, p. 16, tradução nossa). A mídia, embora sendo o a priori da percepção, não é o a priori dela mesma; sua emergência é dependente de técnicas, pois "As ferramentas prescrevem seu próprio uso e os objetos possuem seus próprios operadores” (VISMANN, 2013, 
p. 83, tradução nossa).

Essa concepção sui generis de mídia fundamenta não apenas Kittler, mas também as práticas características pelas quais a TAM é conhecida: longas descrições das materialidades da comunicação, beirando as especificidades técnicas tanto dos suportes como dos materiais com que são feitos; objetos de pesquisa cujos contornos jamais estão claros e que claramente, mas não explicitamente, estão para além dos objetos físicos analisados, ainda que estes sejam os objetos dos quais partam as análises. Isso faz com que os objetos de pesquisa se multipliquem: afinal, qualquer coisa pode vir a ser mídia, quer dizer, qualquer forma pode vir a ser a porta de entrada a esse objeto de pesquisa que estamos chamando, grosso modo, medium.

Para muitos dos autores que seguiram os passos de Kittler, não parecia existir qualquer delimitação ou definição axiomática do que poderia vir a ser enquadrado como mídia: essa“não ontologia"(HORN, 2007, tradução nossa) levaria a uma definição tautológica, definindo-a de forma ad hoc. Mesmo nesse caso, a mídia não seria balizada pragmaticamente, já que muitos autores não parecem interessados no que as pessoas fazem com elas (GEISLER, 1999). Ao contrário, a "não ontologia" da mídia define-a a partir dos usos e/ou das demandas do pesquisador, daquilo que ele entende como sendo o elemento nãodiscursivo de um medium específico. Como observa Jussi Parikka, o conceito de mídia da TAM "não é antiontológico per se, mesmo que não se estabeleça sobre uma definição de meios de comunicação reconhecido por uma entidade disciplinar e institucional" (PARIKKA, 2012, p. 10, tradução nossa). Ao tomar a materialidade da mídia como foco primário de análise - a percepção de que "todo ato de comunicação exige a presença de um suporte material para efetivar-se" (FELINTO, 2001, p. 3) -, o perigo é sempre soar "tecnodeterminista", algo que, no senso comum, é "altamente suspeito, se não moralmente depravado", como brinca Winthrop-Young (2011a, p. 14, tradução nossa). Uma consequência direta é a dilatação do conceito de mídia, de forma que uma gama imensa de objetos possa ser estudado enquanto mídia, não limitandose aos consagrados suportes habituais da tradição administrativa norteamericana. Um efeito disto é que nem todo estudo, filosofia e teoria alemã sobre Mídia são, mutatis mutandis, estudos, filosofias e teorias sobre Comunicação. É preciso manter isso em vista, considerando a tradição 
brasileira de pensar as mídias a partir de seus aspectos comunicacionais e não - como os alemães - a partir de suas posições mediais dentro de sistemas complexos de relações. Siegert (2013) aponta que o termo Medien não identifica um foco definido de objetos, mas uma moldura de referência para a investigação dentro das Humanidades, um ponto de vista apoiado por Claus Pias (2016): os Estudos de Mídia seriam uma abordagem capaz de "problematizar"diversas disciplinas das Humanidades (e, no caso brasileiro, Sociais Aplicadas).

Logo, a questão não é a busca por um conceito fechado capaz de validar uma disciplina acadêmica. Afinal, mídia é uma palavra-chave que produz a desestruturação da estrutura acadêmica: seus objetos estão por toda a parte. Isso faz com que alguns dos autores da TAM mais fiéis a Kittler substituam a pergunta "o que são mídias?" por "o que, em determinada circunstância, 'estavam mídias'?” (PIAS, 2011). A resposta a essa questão depende da distinção entre 1) um suporte de mídia, 2) aquilo que elas supostamente medeiam, e 3) como elas servem de meio até o Outro; o que leva a uma construção teórica na qual, partindo da diferenciação entre materialidade e medium, a mídia aparecerá sempre como terceira, em sua condição de medialidade.

Aqui, chega-se a um ponto crucial: mídia e materialidade não são sinônimos; ao mesmo tempo, a materialidade não deixa de ser o suporte do medium. A mídia é definida por sua medialidade, a sua posição como terceiro mediador em um sistema dual articulado entre medium e forma. A materialidade é a forma de expressão do medium - a sua "entidade não discursiva" (ERNST, 2018, p. 44) -, mas não pode ser reduzida jamais à mídia e à sua medialidade. Justamente, qualquer materialidade está, enquanto exterioridade, sempre em risco de se tornar obsoleta como expressão da rede que a articula. Por consequência, há um foco excessivo na dimensão material dos aparelhos e a descrição pormenorizada de seu interior; o entendimento de que esses aparelhos são formações históricas e temporárias, cujo estudo detalhado se assemelharia ao de um fóssil - o que irá desemborcar na Arqueologia das Mídias.

\section{3. "História" na Arqueologia das Mídias}

Para o finlandês Jussi Parikka, treinado na Alemanha, a Arqueologia 
das Mídias é a "escavação das razões de fundo de por que certo [...] aparato de mídia ou hábito de uso é capaz de nascer, ser adotado e se sustentar em uma situação cultural" (PARIKKA, 2012, p. 6, tradução e grifo nosso), sempre do ponto de vista do presente. Se, para McLuhan, o conteúdo de um meio é outro, do ponto de vista de Parikka, a história de uma mídia é outra mídia (mais corretamente, mídias) - daí a ênfase, por exemplo, em artefatos pré-cinematográficos como "entreatos" das mídias e das diversas modulações dos sentidos visuais e auditivos (ZIELINSKI, 1999).

Se essas são as linhas gerais da abordagem, há nuanças nos projetos particulares de cada autor identificado com ela, como Zielinski (1999, 2006), Elsaesser (2018), Ernst $(2017,2018)$ e o próprio Parikka. Todavia, as especificidades parecem se sustentar na construção de um entendimento bastante particular da palavra história, empregada pelos autores de Arqueologia das Mídias como uma maneira de distinção em relação à outra disciplina aparentada, a História das Mídias. Quem dá as coordenadas epistemológicas para essa compreensão de "história", dentro da rede discursiva do pensamento germânico sobre mídias, são o tcheco-brasileiro-alemão Vilém Flusser, cuja influência sobre a TAM precisa ainda ser mais bem estudada 4 , e Hans Ulrich Gumbrecht, junto de Kittler, a principal figura de divulgação da TAM no exterior.

Duas características do pensamento alemão sobre mídias são sua periodização rigorosa e seu modelo de rupturas, quase sempre propagadas por mudanças tecnológicas. O ponto de identificação de uma ruptura radical entre dois modelos de mundo é a Modernidade (cf., como exemplo, KITTLER, 1999), a quebra entre um modelo supostamente linear (histórico), "próprio", que organiza o paradigma hermenêutico; e outro, mecânico e "impróprio", nãolinear, nãohermenêutico, póshistórico. Vilém Flusser, por exemplo, propõe esse modelo de ruptura na oposição entre um sistema linear baseado na escrita por outro nãolinear, poroso e digital. Essa passagem é equacionada à invenção e posterior adoção gradual das mídias técnicas, cuja característica de

\footnotetext{
4 Se tomarmos como correta a periodização do pensamento alemão sobre mídias pós-anos 1970 proposta por PIAS (2016), Flusser estaria em uma espécie de "grau zero", anterior à geração de Kittler e Gumbrecht. Esses dois autores prestam seguidas referências a Flusser, sobretudo Kittler, responsável pela ida do tcheco-brasileiro à Bochum em sua última conferência, publicada no Brasil com o título de Comunicologia (FLUSSER, 2014). Cf. a introdução de Kittler para a publicação.
} 
reprodutibilidade mina o entendimento linear (e narrativo), de um fluxo contínuo em uma só direção. Com isso, a história deixaria de ser um movimento em direção ao progresso para se tornar um anacronismo incapaz de dar conta da atual situação justamente porque seu "sistema de inscrição" é incapaz de transcrever as expressões matemáticas que in-formam o digital (FLUSSER, 2011). Referindo-se à operacionalização de mídia, há nessa estrutura conceitual a dissolução da medialidade que mantinha unida a rede discursiva histórica (o modelo narrativo linear) a seu sistema de inscrição de preferência (a escrita). A partir da Modernidade, como em um fractal, qualquer momento no presente pode - por meio de tecnologias digitais de arquivamento cada vez mais onipresentes - ser conectado a qualquer passado, o que faz da "recursão" - uma palavra que os alemães preferem à "recorrência" - do passado um dos modelos de análise essenciais da Arqueologia das Mídias.

Se isso não é particularmente novo no tipo de crítica após-aModernidade, o frescor de Flusser é fazer colidirem dois regimes distintos, e apostar na diferença como estruturante da forma mais recente. Para ele, um filme conta sua história por meio de uma linha - de um enredo -, portanto, o faz historicamente. Ao mesmo tempo, porque a forma cinema é pós-histórica, gera uma espécie de dissonância entre forma e conteúdo. Logo, o espectador, embora "[...] atue na história e seja determinado por ela, já não está mais interessado na história como tal, mas na possibilidade de combinar várias histórias. Isso significa que para ele a história não é mais um drama [...], mas apenas um jogo" (FLUSSER, 2007, p. 123). A questão aqui não é apenas que uma mídia é o conteúdo da seguinte - o romance para o cinema -, mas que, assim sendo, criase uma situação em que o campo de possíveis da mídia mais recente começa a corroer a anterior. O cinema não apenas inaugura novas possibilidades para "contar" uma história como reconfigura o que era possível fazer nas narrativas em forma de romance. Por isso mesmo - e isso é mais Kittler do que Flusser - que a literatura e outras formas de mídias anteriores são os melhores loci de análise para compreender as possibilidades das mídias mais recentes (vide KITTLER, 1990). Esses são, em linhas bastante gerais, os contornos iniciais da Arqueologia das Mídias.

Uma das primeiras consequências dessa "crise da História linear" é o tipo de pensamento histórico que se torna possível na própria filosofia 
de Flusser. Ao pensar a história não como um acúmulo de passado em direção a um futuro aberto, mas como uma espiral em que as imagens pré-históricas encontram as imagens pós-históricas, Flusser oferta o modelo de história que será investigado por Siegfried Zielinski (1999, 2006). Zielinski (2006, p. 19) defende em suas pesquisas sobre o tempo profundo das mídias a existência de "uma preocupação contemporânea a respeito da perda contínua da diversidade". Ele então introduz "uma nova categoria que se contrapõe aopensamento linear: 'excelência', que deve ser medida com referência aos eventos de diversificação e à difusão da diversidade" (ZIELINSKI, 2006, p. 19, grifo nosso). Logo, Zielinski advoga abandonar todas as imagens, ideias e metáforas de progresso contínuo e linear, em prol do que chama tempo circular das mídias. Apesar de não haver citação direta a Flusser - e de Zielinski nunca exatamente conceituar "pensamento linear" -, a estrutura de oposição e rupturas que ele está utilizando é compartilhada pelo filósofo tcheco5.

Já Hans Ulrich Gumbrecht (1999) tenta suspender todas as grandes narrativas filosóficas a respeito da História capazes de emoldurar a sua pesquisa em prol de uma descrição exaustiva das materialidades cotidianas de uma determinada época. O desejo não é, porém, evitar grandes narrativas ou mesmo prescindir de uma filosofia da História. Ao contrário, esse nível só poderia ser acessado a partir da materialidade. Assim, semelhante a Kittler na sua preferência às descrições exaustivas das dimensões materiais e técnicas dos aparelhos, Gumbrecht transpõe esse método à Literatura e à História, dividindo os fenômenos analisados "em duas grandes categorias: fenômenos materiais, tratados como superfícies, e visões de mundo, atingidas através da descrição de conceitos dominantes" (ARAUJO, 2006, p. 321).

Ao menos desde a Querela dos Antigos e Modernos ${ }^{6}$, o conhecimento histórico "começou a se definir como a possibilidade de prever as direções que a História, como um movimento progressivo e abrangente de mudança" (GUMBRECHT, 1999, p. 461). Nessa filosofia da História, o futuro se diferenciaria cumulativamente do passando, marchando

\footnotetext{
5 Não se pode esquecer que Zielinski foi, por muitos anos, o responsável pelo Arquivo Vilém Flusser na Universidade de Artes de Berlim (UdK), onde atualmente leciona.

6 Polêmica intelectual francesa dos séculos XVII e XVIII, que debatia tanto se era possível aprender algo com a História quanto se os feitos dos modernos (aqui no primeiro dos três sentidos identificados por Gumbrecht) algum dia superariam os do mundo clássico.
} 
sempre em direção a "novos futuros, moldados pelos 'horizontes abertos de possibilidades'” (GUMBRECHT, 2015, p. 64). Prensado entre os dois, o presente não seria mais que um "mero momento de transição" (GUMBRECHT, 2015, p. 64). Na virada do século passado, no momento em que a Modernidade se configurava como um momento de transição das sociedades industriais, esse cronótopo que organizou o pensamento sobre os processos históricos teria entrado em crise. Ele continuará a sofrer ao longo do século. Uma vez frustrado o otimismo em relação ao conceito de progresso, o futuro voltaria a ser ameaçador, da mesma forma que era na Idade Média, diz-nos Gumbrecht (2015, p. 66).

Em linhas gerais, isso é o que Gumbrecht identifica como processo de destemporalização (GUMBRECHT, 1998, p. 137-151), cujo resultado é a situação de "nosso amplo presente". No cronótopo anterior, o presente era "imperceptivelmente breve, no qual as ações humanas aconteciam como seleções entre diferentes roteiros possíveis para o futuro" (GUMBRECHT, 1999, p. 468). Agora, ele tornou-se "onipresente", o que caracterizaria a cultura ocidental pós-moderna "pela permanência de um presente infindável” (FELINTO, 2001, p. 9). Não escapara também a Flusser que a explosão de um horizonte histórico e linear de progresso, em substituição ao interesse crescente por ferramentas contra-históricas como os bancos de dados, levaria ao abandono do futuro (FLUSSER, 2011). Porém, ao contrário de Gumbrecht, a inspiração de Flusser parece vir da Escola de Frankfurt e sua desconfiança da ideia de progresso, e não necessariamente do processo de destemporalização. Nesse sentido, para Flusser, a crise histórica é a consequência do progresso tecnológico ao longo do século XX; enquanto que, para Gumbrecht, não existe causação estabelecida a priori; ou, quando existe, ela é mais "discursiva" e menos materialista, sendo periférica à Modernidade.

As contribuições de Flusser e Gumbrecht à palavra história dentro da TAM desenham as possibilidades epistemológicas e metodológicas da Arqueologia das Mídias. Primeiro, a insistência na ruptura entre um modelo linear de história e outro, "não-linear" (Flusser) e "nãohermenêutico" (Gumbrecht), sustenta a caracterização da "pós-histórica" Arqueologia das Mídias como uma negação da História das Mídias. Segundo, a certeza de uma catástrofe iminente leva à investigação do arquivo de memória em buscas de novas possibilidades para o presente. Isso atiça o interesse por histórias contrafatuais, alternativas, 
variantes e imaginárias (ELSAESSER, 2018; KLUITENBERG, 2011). A tentativa é de atualizar futuros esquecidos e manter sempre provisórias as articulações que levariam ao fim do futuro. Logo, história é ativamente construída como um espantalho teórico que serve de contra-argumento à proposição da necessidade da Arqueologia das Mídias, o que faz com que continue aparecendo nos textos de discussão sobre "o que é" a abordagem (PARIKKA, 2012; HUHTAMO, PARIKKA, 2011; ELSAESSER, 2018).

\section{Considerações finais}

De acordo com o canadense Geoffrey Winthrop-Young (2011a, p. 14), o primeiro estrangeiro a recomendar "German Media Theory" para audiências não germanófonas foi o teórico holandês Geert Lovink, em meados dos anos 2000, quando direcionou a atenção da academia de língua inglesa àquela reflexão alemã influenciada pelo pós-estruturalismo, pela teoria sistêmica e, em menor grau, também pelo cognitivismo. 0 fato de um estrangeiro ser o responsável pelo batismo de uma corrente de pensamento conta muito sobre a maneira como a Teoria Alemã das Mídias (doravante TAM) é compreendida mundialmente. Assim como a recepção estadunidense da Escola de Toronto de McLuhan, a produção de alguns autores estrangeiros é tomada como característica de uma abordagem delimitada por fronteiras linguística e/ou geopolítica, aglutinadas através desse olhar de fora. Isso leva os alemães a se perguntarem "o que há de alemão na Teoria Alemã das Mídias?" (PIAS, 2016, tradução nossa).

Alguns autores atribuem o caráter "excepcional" dos Estudos de Mídia na Alemanha à existência de faculdades de mídia ${ }^{7}$ alocadas em departamentos de Ciências Humanas ${ }^{8}$. Todavia, a mera alocação, no mesmo departamento, dos Estudos de Mídia junto de Cinema (Film), Fotografia, Teatro e/ou Música não é pioneiro, tampouco tardio, em

\footnotetext{
7 Na fala de Hans Ulrich Gumbrecht: "What is self-evident here, is absent elsewhere. We don't find media studies faculties in other countries. This is a fact" (apud LOVINK, 2009, on-line).

8 À guisa do argumento, estamos desconsiderando os cursos de comunicação em Fachhochschule, caracterizadas por uma vinculação maior com o mercado (professores são escolhidos a partir de suas carreiras profissionais) e a incapacidade de conferir o grau de doutor. Para o argumento, consideramos as vinculações dos estudos sobre mídia não apenas em institutos de educação superior, mas de estudos especializados sobre o assunto.
} 
comparação com outros países. O que há de fato inédito na constituição do campo na Alemanha, e o que precisa ser levado em conta, é a estranha falta de relação entre Estudos de Mídia e Estudos em Comunicação. Esse suposto antagonismo entre o que nós chamamos de Ciências Humanas, de um lado, e Ciências Sociais, de outro, está no horizonte da preocupação de Friedrich Kittler (1993) em propor um modelo substituto aos estudos humanísticos capaz de incluir dimensões técnicas e tecnológicas. Também está na raiz da tendência da TAM em evitar analisar as dimensões econômicas e políticas dos agentes mediáticos, contando uma história das mídias independente dos agentes humanos ${ }^{9}$. Mais do que exemplo de um suposto "estruturalismo hardcore", essa é uma maneira de contrapor-se, na ecologia das teorias de mídia na Alemanha, ao domínio dos teóricos da Escola de Frankfurt - a quem, aliás, Friedrich Kittler reserva o desagradável apelido de "filósofos hobbystas" (KITTLER, 2006, p. 263; citado em WINTHROP-YOUNG, 2011b, p. 85).

No nosso entender, o Sonderweg (excepcionalismo) dos Estudos de Mídia germânicos - uma expressão, aliás, carregada de um nefasto passado político, utilizada pelos próprios epígonos quando desejam explicitar o ineditismo da abordagem alemã (vide LOVINK, 2009) - não está nessa organização acadêmica, ou sequer pode ser encontrado como mais uma historiografia que descreve um arco de Kittler às Técnicas Culturais pós-kittlerianas. Entendemos que "o que há de alemão na Teoria Alemã das Mídias" é o compartilhamento de compreensões bastante específicas de certas palavras-chave que servem de combustivo para o pensamento alemão a respeito das mídias. Uma dessas palavras-chave é a própria mídia: ainda que Kittler jamais tenha dado uma conceituação redonda dela, salvo caracterizá-la por três operações (armazenamento, processamento e transmissão), ele ancorase em um sentido compartilhado e difundido na Alemanha, que o liga à recepção germânica de Aristóteles (conforme apontam SEITTER, 2015 e BASTOS, 2012). Nesse sentido, "mídia”, ao menos em Kittler, é um "jádado" que prescinde de uma conceituação específica, mas que, mesmo assim, estrutura um edifício teórico ímpar no mundo. Isso não exclui, evidentemente, a intensa reflexão que os alemães têm dado ao conceito

9 Há exceções, como Siegfried Zielinski (na Arqueologia das Mídias) e os "grandes homens" (quase sempre cientistas e militares) de Kittler. Da mesma maneira, a Kulturtechniken considera sua principal contribuição a "reinserção" do humano à TAM. 
desde os anos 1990, com particular intensidade após o falecimento de Kittler no início da presente década. Um estudo comparado da evolução do termo mídia para o(s) conceito(s) mídia poderia nos demonstrar o processo de construção pela qual passa toda teoria.

Da maneira um pouco diferente, a palavra-chave história serve de tela para alguns pensadores (sobretudo Flusser e Gumbrecht) pintarem uma compreensão de "pós-história" que substancia muito dos pressupostos metodológicos da Arqueologia das Mídias. A inclusão de "história" como uma palavra-chave a ser pesquisada deve-se ao fato de que, assim como a palavra mídia, ela jamais aparece como um conceito nos escritos da TAM; em verdade, sequer "pós-história", mas esse jogo de oposições está implícito toda vez em que se lê algum texto de Arqueologia das Mídias.

Como esperamos ter deixado claro, este artigo não é apenas uma revisão teórica. Ele ancora-se sobre uma hipótese: a existência de redes discursivas teóricas que servem de infraestrutura para os processos de pensamento sobre a comunicação. Quando se pensa dentro e a partir dessa rede teórica, algumas palavras são tomadas como autoevidentes e desnecessárias de maior exploração, pois os sentidos delas são compartilhados entre os agentes de um meio específico.

Extrapolando para além da TAM, seria possível pensar como cada grande tradição em estudos de comunicação pode ser tomada, subrepticiamente, como o início de uma rede discursiva que pensa sobre a comunicação. A filiação a uma ou outra rede nem sempre é um ato consciente; depende do agenciamento de diversas situações que podem ou não coincidir com as fronteiras linguísticas e/ou geográficas; ou, então, de uma rede discursiva adotada a partir de estudos específicos. Isso sugere uma espécie de dimensão comunicacional do pensamento teórico que, julgamos, mereceria ser melhor investigada.

\section{REFERÊNCIAS}

ARAÚJO, Valdei Lopes de. Para além da autoconsciência moderna: a historiografia de Hans Ulrich Gumbrecht. Varia História, v. 22, n. 36, p. 314-328, jul.-dez. 2006.

BASTOS, Marcus T. Medium, media, mediação e midiatização. In: M.A. MATTOS; J.S. JANOTTI Jr.; N. JACKS (orgs.), Mediação \& Midiatização. Salvador: EDUFBA, 2012, p. 53-78. 
ELSAESSER, Thomas. Cinema como Arqueologia das Mídias. Trad. Carlos Szlak, São Paulo: Edições Sesc São Paulo, 2018.

ERNST, Wolfgang. The Delayed Present: media-induced tempor(e)alities \& techno-traumatic irritations of 'the contemporary'. Berlim: Sternberg Press, 2017.

Arqueografia da midia: método e maquina versus história e narrativa da midia. In: BASTOS, Marcus; ALY, Natália (Orgs). Audiovisual experimental: Arqueologias, diálogos, desdobramentos. São Paulo: Pontocom, 2018, p. 23-50.

FELINTO, Erick. Materialidades da Comunicação: Por um Novo Lugar da Matéria na Teoria da Comunicação. Ciberlegenda, n. 5, Rio de Janeiro, RJ: 2001.

FLUSSER, Vilém. O mundo codificado: por uma filosofia do design e da comunicação. Org.: Rafael Cardoso. São Paulo: Cosac Naify, 2007

Pós-História: vinte instantâneos e um modo de usar. São Paulo: Annablume, 2011.

Comunicologia: reflexões sobre o futuro. São Paulo: Martins Fontes, 2014.

GEISLER, Michael. From Building Blocks to Radical Construction: West German Media Theory since 1984. New German Critique, n. 78, p. 75-107, 1999.

GEOGHEGAN, Bernard D. After Kittler: on the cultural techniques of recent German media theory. Theory, Culture \& Society, v. 30, n. 6, p. 66-82, 2013

GUMBRECHT, Hans Ulrich. Em 1926: vivendo no limite do tempo. Rio de Janeiro/São Paulo: Editora Record, 1999.

Nosso amplo presente. São Paulo: Editora Unesp, 2015.

HORN, Eva. Editor's Introduction: “There Are No Media”. Grey Room, n. 29, p. 7-13, 2007.

HUHTAMO, Erkki; PARIIKKA, Jussi. Introduction: an archaeology of media archaeology. In: HUHTAMO, E,; PARIKKA, J, (Orgs.). Media Archaeology: approaches, applications, and implications. Berkeley, Los Angeles, Londres: University of California Press, 2011, p. 1-21.

KITTLER, Friedrich A. Discourse Networks: 1800-1900. Stanford, EUA: Stanford University Press, 1990.

Den Riß zwischen Lesen und Schreiben überwinden: Im Computerzeitalter stehen die Geisteswissenschaften unter Reformdruck. Frankfurter Rundschau, 12 de janeiro de 1993.

Gramophone, Film, Typewriter. Stanford, EUA: Stanford University Press, 1999.

Musik und Mathematik I. Hellas 1: Aphrodite. Munique, Alemanha: Fink, 2006.

KLUITENBERG, Eric. On the Archaeology of Imaginary Media. In: HUHTAMO, Erkki; PARIKKA, Jussi (Orgs.). Media Archaeology: approaches, applications, and implications. Berkeley, Los Angeles, Londres: University of California Press, 2011, p. 48-69.

LOVINK, Geert. Debating German Media Theory in Siegen. 23 de abril de 2009. Disponível em: <http:// networkcultures.org/geert/2009/04/23/debating-german-media-theory-in-siegen/>. Acesso em 24 de novembro de 2018.

PARIKKA, Jussi. What is media archeology?Cambridge, EUA: Polity Press, 2012. 
PIAS, Claus. Was waren Medien-Wissenschaften? Stichworte zu einer Standortbestimmung. In: PIAS, Claus. (Org.) Was Waren Medien? Zurique: diaphanes, 2011b, p. 7-30.

. What's German About German Media Theory? In: FRIESEN, Norm. (Org.). Media Transatlantic: Developments in Media and Communication Studies between North American and German-speaking Europe. Basiléia: Springer International, 2016, p.15-27.

SEITTER, Walter. [Meta]physics of Media. In: HERZOGENRATH, B. (Org.) media|matter: the materiality of medialmatter as medium. Nova lorque: Bloomsbury Academic, 2015, p. 19-27.

SIEGERT, Bernard. Cultural Techniques: or the end of the intellectual postwar era in German Media Theory. Theory, Culture \& Society, v. 30, n. 6, p. 48-65, 2013.

SPRENGER, Florian. Academic Networks 1982/2016: the provocations of a reading. Grey Room, n. 63, p. 70-89, 2016.

TOCQUEVILLE, Alexis. A democracia na América. Trad. Neil Ribeiro da Silva. 1. ed. Sâo Paulo: Folha de S.Paulo, 2010

VISMANN, Cornelia. Cultural techniques \& sovereignty. Theory, Culture \& Society, v. 30, n. 6, p. 8393, 2013.

VOGL, Joseph. Becoming-media: Galileo's Telescope. Grey Room, n. 29, p. 14-25, 2007.

WILLIAMS, Raymond. Keywords: A Vocabulary of Culture and Society. Oxford: Oxford University Press, 2015.

WINTHROP-YOUNG, Geoffrey. Krautrock, Heidegger, Bogeyman: Kittler in the anglosphere. Thesis Eleven, v. 107, n. 1, p. 6-20, 2011 a.

Kittler and the Media. Cambridge, Reino Unido: Polity Press, 2011b.

ZIELINSKI, Siegfried. Audiovisions: Cinema and television as entr'actes in history. Amsterdã: Amsterdam University Press, 1999.

Arqueologia da mídia: em busca do tempo remoto das técnicas do ver e do ouvir. São Paulo: Annablumme, 2006. 


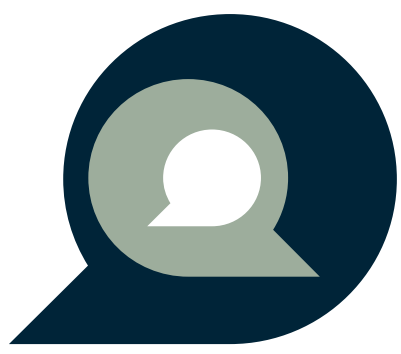

